\title{
Acute Bilineal Leukemia
}

National Cancer Institute

\section{Source}

National Cancer Institute. Acute Bilineal Leukemia. NCI Thesaurus. Code C6923.

An acute leukemia of ambiguous lineage in which there is a dual population of blasts with each population expressing markers of a distinct lineage (myeloid and lymphoid or B-and T-lymphocyte). (WHO, 2001) 